Conclusion: Using Fine-Gray proportional hazard regression, we demonstrated that RF positivity was related to a higher discontinuation rate of TNFi therapy due to ineffectiveness in bio-naïve RA patients.

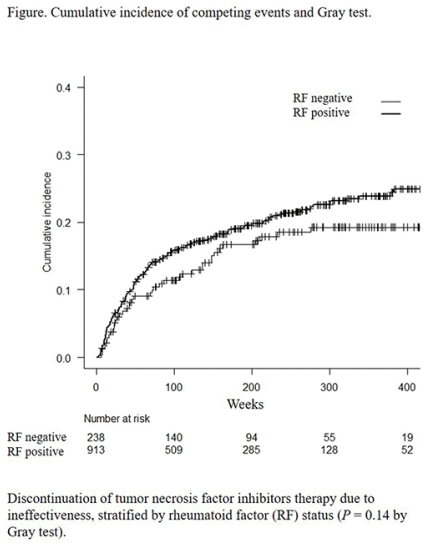

Table 1. Characteristics of RA patients at baseline by RF status.

\begin{tabular}{|c|c|c|c|}
\hline & \multicolumn{3}{|c|}{$\operatorname{RF}(n=1151$} \\
\hline & \multicolumn{3}{|c|}{3407 patient-years) } \\
\hline & $\begin{array}{c}\mathrm{RF} \\
\text { positive } \\
(\mathrm{n}=913)\end{array}$ & $\begin{array}{c}\text { RF } \\
\text { negative } \\
(n=238)\end{array}$ & $P \dagger$ \\
\hline Age, years (SD) & $56.6(13.5)$ & $53.1(14.7)$ & $<0.001$ \\
\hline Female, no. (\%) & $737(80.8)$ & $195(82.3)$ & 0.64 \\
\hline DAS28ESR (SD) & $5.28(1.33)$ & $4.87(1.38)$ & $<0.001$ \\
\hline Stage $\mathrm{I}+\mathrm{II} / \mathrm{II}+\mathrm{IV}$, no. (\%) & $\begin{array}{c}312 / 569(35.4 / \\
64.6)\end{array}$ & $\begin{array}{c}103 / 120(46.2 / \\
53.8)\end{array}$ & 0.0032 \\
\hline Class I+II/III+IV, no. (\%) & $\begin{array}{c}543 / 338(61.6 / \\
38.4)\end{array}$ & $174 / 49(78 / 22)$ & $<0.001$ \\
\hline $\begin{array}{l}\text { Current MTX treatment, no. } \\
(\%)\end{array}$ & $584(82.7)$ & $191(90.1)$ & 0.009 \\
\hline Current PSL treatment, no. (\%) & $383(58.1)$ & $98(51.0)$ & 0.083 \\
\hline \multicolumn{4}{|c|}{$\begin{array}{l}\text { Data are presented as mean, unless otherwise stated. SD: standard deviation; RA: } \\
\text { rheumatoid arthritis; RF: rheumatoid factor; MTX: methotrexate; PSL: prednisolone; } \\
\text { DAS28ESR: Disease Activity Score in } 28 \text { joints calculated with erythrocyte sedimentation } \\
\text { rate. } \dagger \text { Chi-square test for categorical variables and t-test for continuous variables. }\end{array}$} \\
\hline \multicolumn{4}{|l|}{ Model including RF status $(n=643)$} \\
\hline Variable & $\mathrm{HR}$ & & $P$ \\
\hline RF positive & & & 0.023 \\
\hline Age at baseline & & & 0.035 \\
\hline Sex (referent: male) & 0.8 & & 0.63 \\
\hline Methotrexate use & & & 0.069 \\
\hline Prednisolone use & & & 0.31 \\
\hline $\begin{array}{l}\text { Stage III + IV (referent: I + } \\
\text { II) }\end{array}$ & & & 0.97 \\
\hline $\begin{array}{l}\text { Class III + IV (referent: I + } \\
\text { II) }\end{array}$ & & & 0.67 \\
\hline DAS28ESR at baseline & & & $<0.001$ \\
\hline
\end{tabular}

Disclosure of Interests: Yoshikazu Ogawa: None declared, Nobunori Takahashi Speakers bureau: AbbVie, Bristol-Myers Squibb, Chugai, Eisai, Mitsubishi Tanabe, and Pfizer. YS has received speakers' fees from Astellas, Bristol-Myers Squibb, and Ono, Toshihisa Kojima Grant/research support from: Chugai Pharmaceutical (Investigator Initiated Study), Novartis, Nippon Kayaku, Eli Lilly, Eisai, Speakers bureau: Chugai Pharmaceutical, Takeda Pharmaceutical, Pfizer, Eli Lilly Japan, Bristol Myers Squibb, Ono Pharmaceutical, Daiichi Sankyo, Astelas, UCB, Janssen Pharmaceutical, Tanabe Mitsubishi, Naoki Ishiguro Grant/research support from: AbbVie, Asahi Kasei, Astellas, Chugai, Daiichi-Sankyo, Eisai, Kaken, Mitsubishi Tanabe, Otsuka, Pfizer, Takeda, and Zimmer Biomet,
Consultant for: Ono, Speakers bureau: Astellas, Bristol-Myers Squibb, Daiichi-Sankyo, Eli Lilly, Pfizer, and Taisho Toyama DOI: 10.1136/annrheumdis-2019-eular.4077

\section{FRI0112 INCREASED RISK OF SEVERE INFECTION RECURRENCE IN PATIENTS WHO DEVELOPED SEVERE INFECTIONS DURING BDMARDS THERAPY: A STUDY OF THE MIRAI COHORT}

Eri Oguro ${ }^{1}$, Yuji Yoshida ${ }^{1}$, Kentaro Kuzuya ${ }^{1}$, Yasutaka Okita ${ }^{1}$,

Hidetoshi Matsuoka ${ }^{1}$, Satoru Teshigawara ${ }^{1}$, Maiko Yoshimura $^{1}$, Kentaro Isoda $^{1}$, Yoshinori Haradaa ${ }^{1}$, Shiro Ohshima ${ }^{1}$, Jun Hashimoto', Yukihiko Saeki ${ }^{2}{ }^{1}$ Osaka Minami Medical Center, Department of Rheumatology and Allergology, Kawachinagano, Osaka, Japan; ${ }^{2}$ Osaka Minami Medical Center, Department of Clinical Research, Kawachinagano, Osaka, Japan

Background: One of the most important complications of biological dis ease-modifying antirheumatic drugs (bDMARDs) is severe infection, and management of patients who develop severe infection during treatment with bDMARDs is a great concern. However, no consensus exists regarding bDMARDs readministration following treatment for bDMARDs-associated infection.

Objectives: We elucidated risk factors associated with severe infection recurrence in patients who developed severe infections during bDMARDs therapy. Severe infection was defined as an infection requiring hospitalization. Moreover, we analyzed whether bDMARDs readministration after severe infection in patients with rheumatoid arthritis (RA) was a risk for severe infection recurrence.

Methods: The study sample comprised patients with RA who were examined and prescribed bDMARDs at Osaka Minami Medical Center between January 2010 and December 2017, as part of the MiRAi cohort. The patients who developed severe infections during bDMARDs treatment were followed-up for 12 months. Logistic regression analysis was performed using baseline disease activity, baseline treatment, and disease activity and treatment during the 12-month period.

Results: Severe infections developed in 164 of a total of 1192 patients who were treated with bDMARDs during the study period, and the severe infection rate was $5.73 / 100$ patients-years. Among the 164 patients, bDMARDs were readministered in 130 (79.3\%), whereas treatment with bDMARDs was discontinued in 34 patients (20.7\%). We observed 31 cases of patients with severe infections during the follow-up period (18.9/ 100 patients-years), of which 20 patients (15.4/100 patients-years) belonged to the bDMARDs readministration group and 11 (32.4/100 patients-years) belonged to the bDMARDs discontinuation group. The adjusted odds ratio (OR) for severe infection recurrence within 12 months in the bDMARDs readministration group was 0.39 [95\% confidence interval $(\mathrm{Cl})$ 0.16-0.96]. At 12 months after infection, high-dose prednisolone treatment (adjusted OR 1.35, 95\% $\mathrm{Cl} 1.08-1.69$ ), high C-reactive protein level (adjusted OR 1.28,95\% Cl 1.02-1.62), and low serum albumin levels (adjusted OR $0.30,95 \% \mathrm{Cl} 0.01-0.89$ ) were associated with high risk of severe infection recurrence (Figure)

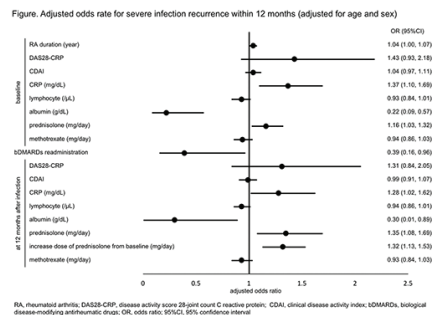

Conclusion: Patients who developed severe infection during bDMARDs treatment were at an extremely high risk for severe infection irrespective of the readministration or discontinuation of bDMARDs after infection. Discontinuation of bDMARDs, high dose of prednisolone 12 months after infection, high levels of C-reactive protein 12 months after infection, and low levels of albumin 12 months after infection were identified as risk factors for severe infection recurrence in these patients. However, bDMARDs readministration did not increase the risk of severe infection recurrence.

\section{REFERENCE:}

[1] Ramiro et al, Ann Rheum Dis 2017;76:1093-1101. 
Disclosure of Interests: Eri Oguro: None declared, Yuji Yoshida: None declared, Kentaro Kuzuya: None declared, Yasutaka Okita: None declared, Hidetoshi Matsuoka: None declared, Satoru Teshigawara: None declared, Maiko Yoshimura: None declared, Kentaro Isoda: None declared, Yoshinori Harada: None declared, Shiro Ohshima Grant/research support from: AbbVie, Eisai, Asahikasei, Speakers bureau: AbbVie, Eisai, Bristol-Meyers, Novartis, Astellas, Nippon-Kayaku, Pfizer, UCB, Ayumi, Daiichi-Sankyo, Takeda, Tanabe-Matsubishi, Chugai, Jun Hashimoto: None declared, Yukihiko Saeki: None declared

DOI: 10.1136/annrheumdis-2019-eular.5581

\section{FRI0113 COMPARISON OF INFECTION-RELATED HOSPITALIZATION COSTS IN PATIENTS WITH RHEUMATOID ARTHRITIS (RA) TREATED WITH ABATACEPT OR OTHER TARGETED DISEASE- MODIFYING ANTI-RHEUMATIC DRUGS (TDMARDS)}

Damemarie Paul, Francis Lobo, Vardhaman Patel, Dhaval Patil. Bristol-Myers Squibb, US HEOR, Lawrence Township, United States of America

Background: Costs due to differences in risk of hospitalized infection associated with targeted disease-modifying anti-rheumatic drugs (tDMARDs) in patients with RA have not been evaluated.

Objectives: Compare the risk and cost of infection-related hospitalizations in tumor necrosis factor inhibitor (TNFi)-experienced RA patients subsequently receiving tDMARDs in the US.

Methods: A retrospective, observational study was conducted with 2 insurance claims databases (MarketScan and PharMetrics; January 1, 2009- June 30, 2017). Analyses were conducted in both datasets individually and in aggregate. The study population was adult TNFi-experienced RA patients initiating a subsequent tDMARD (date of tDMARD therapy=index date). Patients had 12 months of continuous enrollment prior to the index date (baseline period), and were required to have $>1$ inpatient claim or $\geq 2$ outpatient medical claims on 2 different dates with a diagnosis code for RA. Patients with other autoimmune conditions were excluded. Follow-up began with the index date and included $\geq 12$ months ending with the earliest of (1) end of insurance enrollment; (2) end of study period; (3) end of index treatment. Cohorts included (1) abatacept; (2) TNFi: adalimumab, certolizumab pegol, etanercept, golimumab, and infliximab; and (3) other non-TNFi: tocilizumab, rituximab, and tofacitinib. Hospitalized infection costs were measured on a per-patient-per-month (PPPM) basis (2016 USD). Two-part multivariable generalized linear models (GLMs) examined differences in costs. Baseline comorbidities, infection incidence, healthcare costs, payer type, age, gender, and geographic region were used as regression covariates. Log transformation and gamma distribution were applied in GLMs.

Results: Overall, most patients were female $(79 \%)$ with an average age of 52 years. Although a higher percentage $(4.5 \%)$ of patients in the abatacept cohort had a hospital visit for infection in the baseline period compared to TNFi $(2.0 \%, P<0.0001)$ and other non-TNFi $(3.6 \%, P=0.2619)$, the trend reversed in the follow-up period $(2.8 \%$ for abatacept vs $3.7 \%$ for $\mathrm{TNFi}$ and $5.2 \%$ for other non-TNFi; $\mathrm{P}<0.05)$. Regression results indicated a significantly higher risk for hospitalized infection for patients receiving a TNFi [HR: $1.6(95 \% \mathrm{Cl}: 1.1,2.2)]$ or other non-TNFi [HR: 1.9 (95\%: 1.3, 2.8)] vs abatacept. Mean PPPM (95\% Cl) inpatient costs in the follow-up were $\$ 73(\$ 17-\$ 158)$ for abatacept, $\$ 115$ (\$27-\$224) for TNFi, and $\$ 125(\$ 29-\$ 264)$ for other non-TNFi. Difference from baseline to follow-up PPPM inpatient costs was significantly lower for abatacept (difference of $\$ 42$ for TNFi and $\$ 52$ for other non-TNFi, $\mathrm{P}<0.05$ ).

Conclusion: There were significantly lower infection-related hospitalizations and associated costs for TNFi-experienced RA patients who were switched to abatacept compared to patients switched to other therapies. Disclosure of Interests: Damemarie Paul Shareholder of: Bristol-Myers Squibb, Employee of: Damemarie Paul is an employee of Bristol-Myers Squibb., Francis Lobo Shareholder of: Bristol-Myers Squibb, Employee of: Bristol-Myers Squibb, Vardhaman PATEL Employee of: Bristol-Myers Squibb, Dhaval Patil Shareholder of: Bristol-Myers Squibb, Employee of: Bristol-Myers Squibb

DOI: 10.1136/annrheumdis-2019-eular.6270

\section{FRI0114 \\ ABATACEPT IN EARLY RHEUMATOID ARTHRITIS: A SYSTEMATIC LITERATURE REVIEW AND NETWORK META-ANALYSIS}

Damemarie Paul ${ }^{1}$, Leticia Ferri ${ }^{1}$, Grace Crocket $^{1}$, Lauren Mintzer ${ }^{2}$, Mir Sohail Fazeli ${ }^{2} .{ }^{1}$ Bristol-Myers Squibb, Princeton, NJ, United States of America; ${ }^{2}$ Doctor Evidence LLC, Santa Monica, CA, United States of America

Background: Rheumatoid arthritis (RA) is a wide-spread and debilitating disorder that is becoming increasingly relevant in an aging global population. Identifying and treating RA early in disease course is critical for preventing disability and joint damage.

Objectives: The goal of this systematic literature review (SLR) and metaanalysis was to compare the relative efficacy of abatacept (ABA) to other currently recommended therapies for patients with early RA.

Methods: We followed Cochrane guidelines for conducting intervention reviews. Population of interest was adult patients with active RA for $\leq 2$ years treated with recommended therapies per the 2015 ACR guidelines as well as targeted synthetic therapies. Studies of interest were randomized controlled trials (RCTs) and observational studies. Outcomes included ACR50, DAS28, radiographic change, and adverse events where available. A search from January 1998 to June 2018 was performed on MEDLINE ${ }^{\circledR}$, Embase, and the Cochrane CENTRAL databases. Additionally, a hand-search was performed on US and European clinical trials registries from January 2005 to June 2018 and conference proceedings from ACR and EULAR from 2014 to 2018. A Bayesian network metaanalysis (NMA) was performed on the DOC Data ${ }^{\mathrm{TM}}$ platform for the RCTs with reported results on ACR50, DAS28 remission, total withdrawal, and withdrawal due to adverse events.

Results: We identified 90 publications on 69 unique trials reporting efficacy and safety outcomes in patients with early RA, including 43 RCTs and 26 observational studies. The included studies were low risk as assessed by the Cochrane Collaboration's tool for assessing risk of bias. The studies were predominantly double-blind phase III or IV trials. Twenty-eight trials were included in the NMA evaluating ABA $(n=1$ trial), ABA+MTX $(n=2), \quad A D A+M T X(n=6), \quad C T Z+M T X \quad(n=2), \quad \operatorname{ETN}(n=1), \quad$ ETN $+\operatorname{MTX}(n=1), \quad H C Q+S S Z+M T X \quad(n=1), \quad H C Q+S S Z+P r e d+M T X \quad(n=1), \quad$ IFX $+\operatorname{MTX}(n=4), \quad M T X \quad(n=21), \quad$ MPred+MTX $(n=2)$, MPred+Pred+MTX $(n=1)$ Pred $+S S Z+M T X(n=2)$, Pred $+\operatorname{MTX}(n=4)$, Pred $(n=1)$, SSZ $(n=4)$, SSZ $+\operatorname{MTX}(n=2), \quad \operatorname{TCZ}(n=2), \quad \operatorname{TCZ}+\operatorname{MTX}(n=2), \quad$ TOF $(n=2)$, and TOF+MTX $(n=2)$. Abatacept as monotherapy was similar to the combination of $A B A$ and methotrexate for efficacy outcomes, ACR 50 (ABA vs ABA+MTX RR $0.82[95 \% \mathrm{Cl} 0.51-1.35]$ ), and DAS28 Remission (RR $0.76[95 \% \mathrm{Cl} 0.39$ 1.49]), as well as for all-cause withdrawal (RR $1.8[95 \% \mathrm{Cl} 0.91-3.2]$ ) and withdrawal due to adverse events (RR $2.35[95 \% \mathrm{Cl}$ 0.69-7.38]) Both $\mathrm{ABA}$ as monotherapy and $\mathrm{ABA}+\mathrm{MTX}$ were similar to all other comparators (as monotherapy or combination therapy) with respect to main efficacy and safety outcomes. Data reported in observational studies was in concert with the RCT analysis.

Conclusion: The results of this NMA demonstrate similar efficacy between ABA and other biologics both as monotherapy and in combination with traditional DMARDS in early RA. Further investigation and comparison of different treatment options for early RA is warranted as the growing evidence base evolves in favor of using more novel therapies for RA $\mathrm{ABA}=$ abatacept; $\mathrm{ADA}=$ adalimumab; $\mathrm{CTZ}=$ certolizumab; $\mathrm{ETN}=$ etanercept; $\mathrm{HCQ}=$ hydroxychloroquine, IFX= infliximab, MPred= methylprednisolone, $\mathrm{MTX}=$ methotrexate; Pred=prednisone, $\mathrm{SSZ}=$ sulfasalazine, $\mathrm{TCZ}=$ tocilizumab TOF=tofacitinib

Disclosure of Interests: Damemarie Paul Shareholder of: Bristol-Myers Squibb, Employee of: Damemarie Paul is an employee of Bristol-Myers Squibb., Leticia Ferri Shareholder of: Bristol-Myers Squibb, Employee of: Bristol-Myers Squibb, Grace Crocket Consultant for: Grace Crocket is a consultant for Bristol-Myers Squibb., Lauren Mintzer Grant/research support from: Lauren Mintzer is an employee of Doctor Evidence LLC, and the study was funded by Bristol-Myers Squibb., Mir Sohail Fazeli Grant research support from: Mir Sohail Fazeli is an employee of Doctor Evidence LLC, and the study was funded by Bristol-Myers Squibb. DOI: 10.1136/annrheumdis-2019-eular.5179

\section{FRI0115 \\ TRAJECTORIES OF THE EQ-5D SCORE AMONG A LARGE COHORT OF RHEUMATOID ARTHRITIS PATIENTS TREATED WITH BIOLOGICAL DMARDS USING THE IORRA COHORT}

Kumiko Saka $^{1}$, Eiichi Tanaka ${ }^{1}$, Eisuke Inoue ${ }^{2}$, Mai Abe $^{1}$, Mika Kawano ${ }^{1}$, Eri Sugano $^{1}$, Naohiro Sugitani ${ }^{1,3}$, Moeko Ochiai ${ }^{1}$, Yoko Shimizu $^{1}$, Rei Yamaguchi ${ }^{1}$, Naoki Sugimoto ${ }^{1}$, Katsunori Ikari ${ }^{1}$, Ayako Nakajima ${ }^{3}$, Atsuo Taniguchi ${ }^{1}$, Hisashi Yamanaka'. ${ }^{1}$ Tokyo Women's Medical University, Tokyo, Japan; ${ }^{2}$ St Mrianna University School of Medicine, Kanagawa, Japan; ${ }^{3}$ Mie University Hospital, Mie, Japan

Background: Patient-reported outcomes are important for evaluating the disease status of patients with rheumatoid arthritis (RA). The EuroQol five-dimensional descriptive system (EQ-5D) has been used to assess health-related quality of life (QOL) in clinical research and pharmacoeconomic studies. RA is a chronic disease associated with pain, fatigue, dis ability, and functional loss, which can markedly decrease patient QOL. 